\title{
O TESTEMUNHO DE UMA EXPERIÊNCIA HUMANA: UMA ANÁLISE ENUNCIATIVA
}

\author{
Claudia Stumpf Toldo Oudeste \\ Márcio Battisti ${ }^{\mathrm{b}}$
}

\begin{abstract}
RESUMO:
Neste estudo, tomamos como instrumento de análise a teoria da enunciação apresentada na obra de Émile Benveniste (2006, 2005) e o pensamento filosófico de Giorgio Agamben (2008), no que diz respeito à noção de testemunha para descrevermos a relação entre linguagem, homem e língua no processo de construção de um testemunho sobre um caso de agressão a uma professora catarinense, ocorrido em 2017.
\end{abstract}

PALAVRAS-CHAVE: eunciação; testemunha; discurso político.

Recebido em: 31/05/19

Aprovado em: 03/10/19

\section{Introdução}

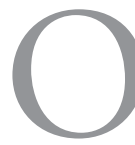

objetivo deste texto é, antes de mais nada, trazer à discussão os termos forma e sentido na linguagem, cunhados no texto de 1966, em conferência ministrada em Genebra pelo linguista Émile Benveniste a filósofos. Gostaríamos de nos deter apenas, mas sabemos não ser possível, na máxima proferida por Benveniste à época de que "bem antes de servir para comunicar, a

a Doutorando do Programa de Pós-graduação em Letras na Universidade de Passo Fundo (UPF/RS). E-mail: marciobattisti4@gmail.com

b Professora tempo integral de Língua Portuguesa e Linguística no Curso de Letras da Universidade de Passo Fundo (UPF/RS). E-mail: claudiast@upf.br 
linguagem serve para viver [...]”. Isso nos traz a premissa de que, sem a linguagem, não há homem, nem sociedade. E essa linguagem traz a significação. Pensemos a partir daqui. Muitos poderiam dizer que a língua realiza, por meio do signo, o ideal do procedimento semiológico, quando instaura o domínio linguístico. Todavia, o mundo do signo apresentado no Curso de Linguística Geral (CLG) é fechado num sistema organizado. A partir disso, Émile Benveniste retoma a noção de signo saussuriano e vai além da questão de oposição do signo apresentada por Saussure e, no texto de 1966, propóe a noção de forma e sentido. Essa noção está relacionada ao universo do discurso e, além disso, à ideia de língua-discurso, a partir da qual, consoante ao exercício individual do uso da língua, o linguista compreende que "nenhuma língua é separável de uma função cultural” (1968/ PLG II, p. 24), porque o próprio da linguagem é significar.

Mediante essas colocaçóes, chegamos à justificativa de que o uso da língua revela os testemunhos de violência sofrida pela professora catarinense. Estes constituem a materialidade fundamental da análise que pretendemos construir neste texto. É por meio do uso da língua que o locutor passa a se constituir como sujeito ${ }^{1}$ e, consequentemente, consegue revelar sua experiência na e pela linguagem, bem como sua experiência em relação ao mundo.

Junto aos estudos de Benveniste, trazemos também a noção de testemunho desenvolvida por Giorgio Agamben, no livro O que resta de Auschwitz. Nessa obra, o filósofo italiano analisa a produção literária dos sobreviventes dos campos de concentração nazistas, questionando-se sobre as dificuldades e as impossibilidades de se poder testemunhar sobre uma violência que está além da compreensão humana. Essa análise recai sobre o depoimento do escritor Primo Levi, ex-prisioneiro de Auschwitz, que condicionou sua existência à necessidade de relatar aquilo que vivenciou nos campos de concentração. Nesse sentido, nosso ponto de partida para desenvolvermos essa reflexão é encontrarmos elementos nos estudos de Benveniste e Agamben para compreender de que maneira se pode observar o testemunho da experiência do homem na linguagem, neste caso, os testemunhos escritos pelos internautas

1 Por motivos de tempo e espaço, não abordaremos, neste texto, a noção de sujeito mais detalhadamente. Sugerimos a leitura do seguinte texto: FLORES, V. N. Sujeito da enunciação: singularidade que advém da sintaxe da enunciação, http://www.scielo.br/pdf/delta/ v29n1/05.pdf, 23/05/2019. 
na página da Revista Fórum logo após a notícia do caso de agressão a uma professora catarinense.

Por meio dessa aproximação teórica, tomaremos esses discursos como potência testemunhal representativa da experiência do homem na linguagem capaz de construir valores que remetam às correntes ideológicas de direita e esquerda, as quais caracterizam um momento de polarização política da sociedade brasileira. Para isso, abordaremos a escrita testemunhal em uma articulação com a teoria da enunciação.

\section{Um novo olhar sobre o signo linguístico}

Esta seção se dedica a delimitar um percurso teórico por meio do qual possamos entender o que é Semiologia na concepção de Benveniste. Com intuito de buscar respostas a essa questáo, tomaremos como base, primeiro, o texto A forma e o sentido na linguagem (1966/PLG II), artigo no qual encontramos conceitos importantes para entendermos em quais termos Benveniste se vale da Semiologia, com base em Saussure para, assim, "ultrapassá-lo" no que respeita à significância. Na sequência, visitaremos o texto Semiologia da língua (1969/PLG II), no qual o autor discorre, de modo mais preciso, sobre seu pensamento acerca da semiologia da língua.

No texto A forma e o sentido na linguagem (1966/PLG II), Benveniste distancia-se de análises baseadas simplesmente na forma e propóe uma relação intrínseca entre forma e sentido. Assim, a perspectiva adotada por Benveniste retoma e desenvolve o cerne da teoria de Saussure, a qual compreende "a língua como ligação de forma e sentido a ser captada em diferenças" (NORMAND, 2009, p.101), e estabelece um olhar sobre a língua e a linguística mediante a noção de significação, visto que a função primordial da linguagem é significar. É por compreender uma atividade significante por excelência que a linguagem é responsável pela organização e explicação de realizações individuais e coletivas ligadas ao exercício da linguagem. Conforme afirma Benveniste (1966/ PLG II, p. 222), "se nós colocamos que à falta de linguagem não haveria nem possibilidade de sociedade, nem possibilidade de humanidade, é precisamente porque o próprio da linguagem é, antes de tudo, significar", então é para esse exercício que queremos dar atenção. 
A língua ocupa um lugar particular no universo dos sistemas semiológicos, uma vez que é capaz de interpretar todos os outros sistemas de signos. Desse modo, a língua atua como interpretante da sociedade, capaz de registrar, de designar e de orientar mudanças em relação àquilo que é interpretado. Outro conceito importante que Benveniste menciona sobre a língua é a sua capacidade de falar de si mesma, "daí provém seu poder maior, o de criar um segundo nível de enunciação, em que se torna possível sustentar propósitos significantes sobre a significância” (1969/PLG II, p. 66), criando, assim, uma faculdade metalinguística.

Com base nisso, percebemos que a relação explícita da presença do homem com outro homem no mundo por meio da língua se dá especialmente no nível semântico, que resulta da atividade do locutor de colocar a língua em uso, retirando o signo do nível semiótico e integrando-o ao nível da frase, no qual o sentido implica referência à situação de discurso e à atitude do locutor. $\mathrm{Na}$ instância do discurso, a unidade da frase deixa de ser o signo e assume a condição de palavra, que será preenchida de sentido na frase pelo sujeito que mobiliza a língua. Ao mobilizar a língua e dizer "eu", o locutor torna-se sujeito e, em tempo e espaço específico, constrói a enunciação, por meio da qual assegura sua existência e dá sentido a tudo o que está a sua volta. É da conversão da língua em discurso, do qual emerge o testemunho da experiência humana na linguagem, que trataremos na próxima seção.

Destacamos que toda experiência humana de linguagem está ligada a um fenômeno linguístico.

\section{A noção de testemunha}

Esta seção é dedicada à descrição da noção de testemunha proposta pelo filósofo italiano Giorgio Agamben, no livro O que resta de Auschwitz, com o objetivo de entendermos as especificidades dos testemunhos suscitados pelo caso de agressão à professora de uma escola pública em um tempo de excessiva polarização política no Brasil. Para tal, buscaremos elementos nas reflexões de Benveniste e Agamben para compreendermos de que maneira podemos observar o testemunho da experiência do homem na linguagem. 
Agamben (2008) propóe a noção de testemunho. Para isso, o autor parte do relato de um ex-prisioneiro em Auschwitz, o Primo Levi, para construir um raciocínio acerca dessa noção, a qual implica "o sistema das relaçôes entre o não dito e o dito” (AGAMBEN, 2008, p. 146). Para definir testemunha, o filósofo utiliza-se de dois termos oriundos do latim: testis, que "significa etimologicamente aquele que se póe como terceiro (terstis) em um processo ou em um litígio entre dois contendores" e superstes, que indica "aquele que viveu algo, atravessou até o final um evento e pode, portanto, dar testemunho disso" (AGAMBEN, 2008, p.27). Primo Levi, por exemplo, enquadra-se como testemunha no sentido de superstes, pois sobreviveu ao acontecimento e hoje testemunha sobre ele, não se colocando, em momento algum, como testis porque não se coloca na posição de terceiro entre duas partes, nem na condição de "juiz" diante dos fatos. O testemunho do superstes só faz sentido se vier a integrar o testemunho de quem não pode, por si mesmo, testemunhar.

No âmbito filosófico, conforme menciona o autor, o testemunho remete ao lugar vazio ocupado pelo sujeito, o qual se encontra entre a possibilidade e a impossibilidade de dizer. Isso nos remete à noção de língua em Benveniste, a qual, antes do uso, é apenas possibilidade de língua. Nesse sentido, o sujeito encontra-se em um lugar vazio, visto que é preciso que haja apropriação da língua, para que esta seja convertida em discurso e, por meio disso, institua um sujeito juntamente com a enunciação. Assim, tanto para que haja testemunho quanto para que haja enunciação é necessária a separação constitutiva entre o dizer e o poder não dizer. É essa condição que nos leva a afirmar que a noção de sujeito construída por Agamben não difere da noção de sujeito definida por Benveniste: sujeito como efeito do ato-processo realizado por um locutor que se apropria da língua e enuncia, a sua maneira, aparelhado por ela.

Nessa perspectiva, Agamben (2008) define enunciação como algo único e concreto, dado a capacidade de referir à instância de discurso em ato. Para o filósofo, enunciação é sempre singular e irrepetível, ao mesmo tempo que é vazia e genérica, uma vez que, por mais que algumas escolhas se repitam, não é possível fixar uma realidade lexical. Pensar a enunciação no plano da langue "equivale a inscrever na possibilidade uma cisão que a divide em 
uma possibilidade e uma impossibilidade, em uma potência e uma impotência, e, nessa cisão, situar um sujeito" (AGAMBEN, 2008, p. 146). Ao situar o sujeito, contrapóem-se as noçôes de arquivo e de testemunha, em que arquivo designa um sistema de relaçóes entre o não-dito e o dito, ou como o invisível, que pode ser dito e inscrito em cada dito. Ele é compreendido como uma espécie de eco, de fragmento de memória perdido no tempo e que se apaga tão logo se diz "eu". A constituiçẫo do arquivo pressupóe deixar o sujeito de fora, reduzido a simples função ou a uma posição vazia, apagado no rumor anônimo dos enunciados. Em oposição ao arquivo, testemunho é definido como o sistema das relaçóes entre o dentro e o fora da langue, entre o dizível e o não dizível em toda língua. Aqui, a questão decisiva passa a ser o lugar vazio do sujeito.

Do ponto de vista defendido por Agamben (2008), a passagem da língua para o discurso é paradoxal, uma vez que requer tanto um processo de subjetivação quanto um processo de dessubjetivação. Essa afirmação se baseia na potência exigida do sujeito psicossomático para que ele se torne um sujeito da enunciação. Para que isso aconteça, ele deve, primeiro, dessubjetivar-se, abolindo integralmente sua figura enquanto indivíduo real, para, então, tornar-se sujeito da enunciação e identificar-se com o "eu", substancialmente vazio e de existência atrelada à referência e à instância discursiva. Uma vez livre de qualquer realidade extralinguística e já constituído em sujeito da enunciação, o homem percebe que não é capaz de acessar a palavra, pois se vê "precedido por uma potência glossolálica, sobre a qual não tem controle nem pressa” (AGAMBEN, 2008, p. 121), já que a língua é sistêmica e atualizada na e pela enunciação. Ao dizer "Eu, tu, isso, agora [...], ele acabou expropriado de qualquer realidade referencial, para deixar-se definir unicamente pela relação pura e vazia com a instância do discurso" (AGAMBEN, 2008, p. 121).

A enunciação, acontecimento sempre único, é a garantia para que o homem irrompa em língua e, na instância discursiva que o contém como locutor, aparelhado pela língua, ao dizer "eu", possa iniciar sua aventura pela linguagem. A partir do momento que se diz "eu", a enunciação torna o homem vivo e coloca-o diante de um universo semântico. É nesse sentido que Benveniste deixa claro que a linguagem serve para viver, e a enunciação 
é que garante, no e pelo uso da língua, espaço para o homem no mundo sustentado pela instância do discurso que o contém. A língua é o meio pelo qual o locutor constrói o modo de testemunhar, para existir e para revelar sua experiência, sua existência. Portanto, as reflexóes enunciativas em conjunto com as reflexóes de testemunho amparam nosso olhar para os conceitos de sujeito, sociedade e cultura que emergem dos discursos de ódio, presentes nas redes sociais que defendem atos de violência contra uma educadora.

\section{Apresentação e análise do corpus}

Não só o percurso teórico sobre o qual discorremos neste artigo, como também, de modo mais abrangente, os estudos benvenistianos presentes em seus Problemas de Linguística Geral I e II (2005, 2006) indicam que a capacidade de o sujeito significar o mundo ao seu redor está estritamente ligada à possibilidade de a língua aparelhar o locutor, que, de posse dela, enuncia e subjetiva, atribuindo valor/sentido a tudo aquilo que o cerca. Diante desse contexto, nossa análise preocupa-se com os comentários deixados na página da Revista Fórum sobre o caso de agressão a uma professora da rede pública do município de Indaial, em Santa Catarina, ocorrido no dia 21 de agosto de 2017, dentro da própria escola. Cada testemunho constrói uma realidade discursiva capaz de revelar uma sociedade e, dentro desta, podemos descrever diferentes culturas, seja uma cultura conivente com a violência, seja uma cultura intolerante à violência. Os comentários dos internautas como testemunho da experiência humana na linguagem podem instanciar um centro de referência capaz de suscitar o "eu diante de si" a reviver experiências por meio da potência testemunhal que a plenifica de sentido, tendo por princípio de análise a enunciação benvenistiana, no que diz respeito à semiologia e à filosofia agambeniana referente à noção de testemunho.

Os fragmentos presentes no quadro abaixo correspondem à transcrição de alguns desses comentários. 
Quadro 1: Transcrição dos comentários dos internautas

Comentário 1: Quem semeia, um dia colhe... E de forma bem pior! Bons tempos em que professor se dava ao respeitado dentro das escolas... nos Saudosos tempos dos Governos Militares, cantávamos o Hino Nacional com orgulho, tinha Educação Moral e Civica, OSPB... Quando o professor estava em sala, todos ficavam em sala e se levantavam, em sinal de respeito. Nas escolas militares, isto não ocorre! Jair Messias Bolsonaro 2018! Mesmo que a professorinha covardemente agredida ache bonito ele sofrer agressöes, mesmo que leves e ainda diga que a agressora a representa!

Comentário 2: Ela é petista e comemorou o ataque a Bolsonaro. Graças a Deus que quebraram a cara dela no meio.

Comentário 3: 15 anos. Nasceu em 2012. Geração criada dentro dos benefícios da era do PT com toda "ajuda" social que esse governo pregou e deu. Pq então se criou assim??

Comentário 4: Eis o resultado das políticas de esquerda a longo das últimas décadas no Brasil. Minha solidariedade.

Comentário 5: só vendo que no dos outros é refresco... nada que justifique a covarde agressão, mas está na hora de um basta na esquerdização nas escolas e professores com este tipo de pensamento estúpido! Um dia, viram as vítimas...

Comentário 6: creio que quando um jovem vê que uma pessoa apoia a violência, ele também vai tratar essa pessoa com violência.

Para Benveniste, o valor do signo só pode ser definido na relação com os demais signos dentro de um enunciado. A circunstância que remete ao valor semântico do termo esquerdização se constrói no âmbito de um discurso que traz à tona a polarização das correntes ideológicas de direita e de esquerda, mediante um contexto em que a intolerância política tem sido confundida com opiniāo. A forma esquerdização revela uma sociedade violenta e fechada a qualquer possibilidade de diálogo quando há divergência política. Cria-se, assim, um grupo de extrema-direita, cuja cultura nega a existência de todo e qualquer sujeito que discorde da sua visão política.

O sentido construído em relação ao emprego da forma esquerdização remete a um universo que justifica a agressão, utilizando-se do posicionamento político manifestado pela professora nas redes sociais. Isso se justifica pelas seguintes escolhas: "quem semeia um dia colhe" (comentário 1), "ela é petista" 
(comentário 2), "geração criada dentro dos benefícios da era do PT" (comentário 3), "eis o resultado das políticas de esquerda" (comentário 4), "só vendo que no dos outros é refresco" (comentário 5). Percebemos, desse modo, que a violência não é o centro de referência dos discursos desses internautas. É esse cenário de intolerância política que coloca a professora agredida na mesma posição ocupada pelos muçulmanos nos campos de Auschwitz: uma posição em que o ódio e a truculência impedem a própria existência, porque priva da utilização da língua para revelar suas próprias experiências de vida e de mundo.

Todo ato de enunciação se configura na presença dos índices de pessoa $e u$ e $t u$, em que o eu é definido como o indivíduo que profere a enunciação, já o $t u$, como o indivíduo que está presente como alocutário. Sáo essas categorias de pessoa que, no texto enunciado, evidenciam o lugar-limite constitutivo da enunciação, verificando-se que esses índices se produzem apenas na e pela enunciaçáo e que, por meio disso, remetem às instâncias interna e externa do discurso. Assim, entendemos que os índices mencionados revelam o funcionamento da enunciação, estabelecendo a noção de apropriação da língua pelo sujeito, de acordo com a posiçấo deste no discurso. No que diz respeito aos textos sob análise, o eu do discurso é assumido pelos internautas que, ao se depararem com a leitura da notícia, se apropriam da língua para expressarem um testemunho acerca dos motivos que levaram a professora a ser agredida por um aluno. Agambem (2008) afirma que quem assume a condição de testemunha assume devido à impossibilidade do outro testemunhar. No caso de Auschwitz, são os que "tocaram o fundo", aqueles que já estão mortos ou que, devido aos traumas sofridos, são incapazes de distinguir o bem do mal. Em relaçáo à professora, esta se encontra numa posição de incapacidade de apropriar-se da língua para testemunhar aquilo que ela própria vivenciou. Isso porque sua voz é silenciada por aqueles que assumem a posiçáo de testemunha e buscam, por meio de suas escolhas linguísticas, justificar a agressão, inclusive citando o nome de Deus, e difundir o ódio contra a professora e contra a esquerda brasileira.

A impossibilidade de a professora testemunhar abre espaço para um testemunho que remete a um forte saudosismo em relação ao período da Ditadura Militar no Brasil aliado a um testemunho de patriotismo exagerado. A todo indivíduo que não partilha desse mesmo pensamento é negado o direito 
de testemunhar. Essa impossibilidade de poder dizer se justifica pelo fato de que a violência nas escolas é considerada fruto das políticas governamentais implantadas durante o governo PT. Sendo a professora petista, a culpa pelo ato de violência recai sobre ela. Há, portanto, um testemunho que revela uma sociedade que vê o retorno da Ditadura Militar como solução para os problemas de violência nas escolas, uma vez que esse testemunho considera o período da ditadura aquele no qual a cultura predominante era a do professor que 'se dava ao respeito'.

Conforme Benveniste (1968/PLG II), existe, no emprego da língua, uma força de coesáo capaz de transpor as diferenças existentes no uso individual da linguagem, estabelecendo-a como elemento constitutivo de identidade de uma determinada sociedade. Língua e sociedade configuram-se em uma relação semiológica na qual, "em primeiro lugar, a língua é o interpretante da sociedade; em segundo lugar, a língua contém a sociedade" (1968/PLG II, p. 97). É pelo uso da língua que o sujeito se insere socialmente, e são esses usos que revelam um testemunho de polarização política que tem contribuído significativamente para a construção da identidade da sociedade brasileira. Por exemplo, quando analisamos o comentário "15 anos. Nasceu em 2012. Geração criada dentro dos benefícios da era do PT com toda 'ajuda' social que esse governo pregou e deu. Pq então se criou assim??", evidenciamos que as expressóes "geração" e "era do PT" comprovam a acepção de que há um Brasil ideologicamente dividido. O sentido que se constrói na enunciação para a expressão "geração criada na era do PT" é o de que o governo do PT é o responsável pela criação de alunos violentos em razão dos benefícios e "ajuda" social dados pelo governo PT, durante sua gestão. As marcas linguísticas beneficios e ajuda social, aqui, assumem um valor especificamente negativos e revelam uma direita inconformada com as políticas sociais do governo Lula e do governo Dilma, como o programa Bolsa Família, considerado por esse grupo como um mecanismo capaz de formar uma geração de marginais, conforme o trecho: "eis o resultado das políticas de esquerda a longo das últimas décadas no Brasil”.

A teoria enunciativa de Benveniste também evidencia a relação da linguagem com a realidade. No texto $O$ aparelho formal da enunciação, o autor define que "a língua se acha empregada para expressão de uma certa relação com o mundo" (1970/PLG II, p.84), não o mundo extralinguístico, mas um mundo 
(co)-construído pelos sujeitos falantes, na e pela linguagem, no aqui-e-agora da enunciação. Isso reforça a acepção de que a língua é interpretante da sociedade e que seu uso, portanto, revela certas referências de mundo. Nesse contexto, ato enunciativo "nada que justifique a covarde agressão, mas está na hora de um basta na esquerdização nas escolas e professores com este tipo de pensamento estúpido" remete-se a um testemunho de que tudo o que está ligado ao universo escolar, ideologicamente, pertence à esquerda. A expressão "está na hora de um basta”, mesmo que de modo implícito, refere-se a algo que está no mundo e que é acessado por meio da enunciação, no caso ao Projeto Escola Sem Partido, o qual pretende instituir um modelo de escola livre de concepçóes ideológicas.

Quando o locutor coloca a língua em uso, o signo deixa de pertencer ao nível semiótico e passa a se integrar ao nível da frase, no qual o sentido implica referência à situação discurso e à atitude do locutor. Ou seja, o signo assume a condição de palavra que será preenchida de sentido na frase pelo sujeito que mobiliza a língua. Ao analisarmos o comentário "nada que justifique a covarde agressão, mas está na hora de um basta na esquerdização nas escolas e professores", percebemos que a palavra nada, na verdade, refere-se a muitos fatores, como, por exemplo, a esquerdização nas escolas, aos benefícios e ajuda dados durante a gestão do PT, isto é, quando o locutor diz "nada que justifique", as referências de mundo que emergem do discurso são uma forma de justificar a agressão. Essa noção é reforçada pelo conector mas, que inicia a oração posterior e comprova que há elementos no discurso justificando a violência e afirmando que o sentido da palavra nada, nesse contexto enunciativo, não pode ser o de ausência de justificativa.

A linguagem como experiência humana cria a realidade, engloba a sociedade e revela diferentes culturas. Em um cenário em que uma professora é agredida fisicamente por um aluno e isso se torna justificativa para que ela seja agredida verbalmente em uma rede social, percebemos uma sociedade que menospreza a educação e, ainda, culpa o professor pelo problema de violência existente no país. $\mathrm{O}$ testemunho de cada internauta, enquanto sujeitos viventes na e pela linguagem, é influenciado por uma conjuntura social em que o cenário de polarização política torna o ódio entre a direita e a esquerda o referente para qualquer discurso. $\mathrm{O}$ testemunho de que há um processo de esquerdização coloca as escolas na categoria de defensores da esquerda e, dessa 
postura, resulta uma cultura de depredação da imagem do professor e de falência das instituiçóes de ensino.

É por meio do emprego da língua convertida em enunciação que damos início a uma aventura no universo da significação. É na instância do discurso, criada pelo aparelhamento da língua, que passamos a existir enquanto sujeitos e enquanto sociedade, dentro de um mundo, em que, graças à língua, a tudo podemos atribuir sentido. É a enunciação, portanto, a responsável por nos revelar uma sociedade que quer negar a existência dos professores ao impossibilitá-los de testemunhar suas próprias experiências dentro dos ambientes de ensino. Em uma cultura de desvalorização da imagem do professor e da educação em si, jamais haverá acordo de sentido entre sociedade e escola e isso simboliza o árduo caminho a ser percorrido pela educação na luta pela sobrevivência e pela valorização.

\section{Considerações finais}

Ao desenvolvermos este estudo, verificamos que, por meio da linguística da enunciação de Benveniste e da noção de testemunho descrita por Agamben, é possível percorrer o "lugar-vazio" ocupado pelo sujeito na escrita que, sendo também o sujeito de uma enunciação, encontra na língua um campo de forças que se mobilizam na exterioridade e interioridade do discurso. Dessa forma, pudemos observar como o sujeito, ao tornar possível a palavra, testemunha um silêncio que existe latente no processo de linguagem. Cada internauta, nesse contexto, assume a figura de testemunho, que se manifesta com base em outro testemunho, dado pela Revista Fórum.

As consideraçôes de Benveniste, trabalhadas neste texto, possibilitaram-nos compreender o signo linguístico dentro de uma organização que envolve os eixos semiótico e semântico. Por conseguinte, é no funcionamento da enunciação que emerge a problemática da apropriação da língua pelo sujeito, em conformidade com a posição deste no discurso. Isso porque o indivíduo, ao usar a língua, se insere na cadeia significante como um "lugar vazio", como lacuna entre o que existe como possibilidade de se dizer e o que, de fato, é enunciado. Portanto, testemunhar, mais do que revelar aquilo que estava em silêncio, é tornar-se um sobrevivente da linguagem. 


\section{Referências}

AGAMBEN, Giorgio. O que resta de Auschwitz. Trad. Selvino J. Assmann. São Paulo: Boitempo, 2008.

BENVENISTE, Émile. Problemas de Linguistica Geral I. 5. ed. Tradução Maria da Glória Novak e Maria Luisa Neri. Campinas: Pontes, 2005.

. Problemas de Linguistica Geral II. 2. ed. Tradução Eduardo Guimarães et al. Campinas: Pontes, 2006.

NORMAND, Claudine. Convite à linguística. Tradução Valdir do Nascimento Flores e Leci Borges Barbisan. São Paulo: Contexto, 2009.

SAUSSURE, Ferdinand de. Curso de linguística geral. 27. ed. Tradução Antônio Chelini, José Paulo Paes, Izidoro Blikstein. Organizado por Charles Bally e Albert Sechehaye. São Paulo: Cultrix, 2006.

\section{THE TESTIMONY OF A HUMAN EXPERIENCE: AN ENUNCIATIVE ANALYSIS}

ABSTRACT:

In this study, we take as an instrument of analysis the theory of enunciation presented in the work of Émile Benveniste (2006) and the philosophical thinking of Giorgio Agamben (2008), regarding the notion of testimony to describe the relationship between language, man and language as to ngue in the process of constructing a testimony about a case of aggression against a teacher from Santa Catarina, occurred in 2017.

KEYWORDS: enunciation; testimony; political speech. 
